\title{
Advancement in the Pressureless Sintering of CP Titanium Using High-Frequency Induction Heating
}

\author{
STELLA RAYNOVA, YAN COLLAS, FEI YANG, and LEANDRO BOLZONI
}

\begin{abstract}
High-frequency induction heating is applied as an alternative heating source for pressureless sintering of commercially pure Ti powders, aiming to intensify the sintering process. The effects of the process parameters on the properties of the sintered material are systematically studied. The initial powder compact density is the most influential parameter permitting sintered structures with highly porous to almost fully dense appearance. Short heating time combined with sintering to temperatures just above the $\beta$-transus resulted in a strong diffusion bonding between the Ti powder particles, and grain growth is observed at the former boundaries of the neighboring powder particles. The dimpled appearance of the fracture surface at those regions confirmed the strong metallic interparticle bonding. Tensile properties comparable to those of Ti-Grade 3 and Ti-Grade 4 are achieved, which also demonstrates the efficiency of the induction sintering process. A mechanism explaining the fast and efficient sintering is proposed. The process has the added advantage of minimizing the oxygen pickup.
\end{abstract}

https://doi.org/10.1007/s11661-019-05381-z

(C) The Author(s) 2019, corrected publication 2019

\section{INTRODUCTION}

TitANIUM (Ti) is an ideal material for many structural and advanced engineering applications because of the combination of properties it comprises such as high specific strength, good corrosion resistance, and biocompatibility. However, $\mathrm{Ti}$ is classified as an expensive and difficult-to-process material due to various factors such as complex extraction technology, high affinity for interstitials such as $\mathrm{O}, \mathrm{N}$, and $\mathrm{C}$ as well as to its low thermal conductivity. Powder metallurgy techniques are identified as a potential way to reduce the processing costs of Ti while maintaining acceptable levels of mechanical performance, thus creating a possibility to expand the use of $\mathrm{Ti}$ in general applications such as automotive and sports. Among the powder metallurgy methods, press and sinter is the simplest and widely used technique for powder consolidation. Electric vacuum furnaces are commonly used to sinter Ti-based powders. ${ }^{[1]}$ Because of the slow heating and cooling rates imposed by the way of heat transfer by radiation, the sintering cycle takes around 8 to 12 hours, making the process long and economically inefficient. The

STELLA RAYNOVA, FEI YANG, LEANDRO BOLZONI are with the Waikato Centre of Advanced Materials, School of Engineering, The University of Waikato, Private Bag 3105, Hamilton, 3240, New Zealand. Contact e-mail: stella.raynova@waikato.ac.nz YAN COLLAS is with the ei. CESI de Saint Nazaire, Boulevard de 1 Université, 44600, Saint-Nazaire, France.

Manuscript submitted March 31, 2019.

Article published online August 8, 2019 traditional belt-type continuous sintering furnaces are not suitable for Ti because of the significant contamination from atmospheric gases as well as temperature limitations. ${ }^{[2]}$ Over the last decade, alternative techniques using microwave energy, direct resistance heating, and spark plasma have been explored to intensify the heat penetration beyond traditional limits, to achieve faster sintering. Studies have shown that each one of these techniques has potentially significant benefits but also limitations. For example, spark plasma sintering is a very fast method to obtain fully dense materials but generally, the size and complexity of the part that can be produced is limited. ${ }^{[3]}$ The effectiveness of microwave sintering has been demonstrated on many ceramic systems ${ }^{[4,5]}$ but remains challenging for metallic powders, knowing that metallic materials reflect microwave energy rather than absorb it. ${ }^{[6]}$ High-frequency induction heating (HFIH) is another alternative form of heating which can be applied to conductive materials. ${ }^{[7,8]}$ Early research on using HFIH for sintering of metal powders consider mostly Fe-based powders. Advantages such as simple and relatively inexpensive equipment setup, which can provide fast heating rates, were reported. ${ }^{[8,9]}$ It was shown that heat transfer during induction heating could be 3000 times higher than that of radiation heating. ${ }^{[10]}$ Scientific work on induction sintering (IS) of Fe-based powders reported properties comparable to those of similar powders sintered using conventional vacuum furnaces. ${ }^{[11,12]}$ The shorter IS resulted in finer microstructure, which led to enhanced mechanical properties of the considered ferrous alloys. ${ }^{[12,13]}$ HFIH combined with a simultaneous 
application of pressure is used for rapid consolidation of nanostructured powders such as $\mathrm{TiC}$, TiAl- $\mathrm{Al}_{2} \mathrm{O}_{3},{ }^{[14,15]}$ and more recently $\mathrm{Al}-\mathrm{Fe} .{ }^{[16]}$ In the Ti powder metallurgy, HFIH was used in combination with hot pressing to consolidate Ti powders. ${ }^{[17]}$ Another application is for presintering of $\mathrm{Ti}$ and $\mathrm{Ti} 6 \mathrm{Al} 14 \mathrm{~V}$ powder compacts prior to the final consolidation by hot forging, ${ }^{118,19]}$ thus eliminating lengthy vacuum sintering and the need of reheating. The report on the application of HFIH in pressureless sintering of $\mathrm{Ti}$ powders is limited and mainly associated with the purpose to achieve partial consolidation and improve the strength of the powder compacts prior the final consolidation by hot forging. ${ }^{[2,21]}$ To fill the above gap in the literature, this study investigates the possibility of using HFIH for pressureless IS as a final consolidation stage of commercially pure Ti powders. The presented work considers three main aspects, i.e., the effect of the green density, the effect of the sintering temperature, and the effect of the sintering time, on the physical response of the powder compacts, such as heating rate and level of consolidation. Furthermore, the tensile properties, the fracture behavior, and the oxygen contamination were evaluated, and a mechanism explaining the fast sintering is proposed.

\section{EXPERIMENTAL DESIGN}

The induction sintering of the Ti powders was done in an in-house made experimental setup consisting of a glove box chamber equipped with a copper induction coil externally connected to an HFIH Inductotherm Powertrack 15 to 96 power supply unit, see the sketch in Figure 1(a).

The induction coil carries an alternating current, which creates a magnetic field that induces eddy current in the metal powder compact so that heat is generated directly into the heated object, allowing rapid heating. The efficiency of the heating and the uniform heat distribution in the powder compact depends on the physical properties of the material such as electrical resistivity $(k)$, magnetic permeability $(\mu)$, the geometry of the heated object ( $d$-diameter of the heated object) and the process parameters such as frequency $(f)$. The relation of those parameters with the penetration depth $(\delta)$ is given by Eq. $[1] .^{[8]}$

$$
\delta \sim(1 / k \mu f)^{1 / 2}, 2 \delta<d
$$

To satisfy the experimental conditions allowing sufficient penetration depth, an induction heating power supply working with frequency in the range of 0.1 to 10 $\mathrm{kHz}$ was used. The diameter of the powder compact was $40 \mathrm{~mm}$. The induction coil was with a round design and multiple windings to fully enclose the powder compact, to allow generation of sufficient magnetic field and consequently eddy current through the powder compact height. Figure 1(b) shows the temperature difference, measured via $\mathrm{K}$-type thermocouples, between the center and the periphery of the $\mathrm{Ti}$ powder compact with a relative green density of $89.5 \mathrm{pct}$, during IS to $1000{ }^{\circ} \mathrm{C}$. No significant variation in the temperature trends can be highlighted. Due to the potential experimental errors as physical contact of the thermocouple with the samples, the recorded heating curves and the average heating rates are indicative.

The chamber of the experimental setup is designed to work with continuous argon flow to maintain the oxygen level below $200 \mathrm{ppm}$ during the experiments. An oxygen analyzer Rapidox 3100 was connected to the chamber to monitor the oxygen content. Each sample was induction sintered individually following the required parameter. For the temperature control, a flexible K-type thermocouple was inserted into an inlet made on the top section of the powder compact. During the heating, the power level from the HFIH unit was kept constant. During the holding time at the maximum sintering temperature, the power level was adjusted to maintain the targeted temperature consistent within $\pm 30{ }^{\circ} \mathrm{C}$. The heating rates were established manually by recording the time for every $50{ }^{\circ} \mathrm{C}$ temperature increase.

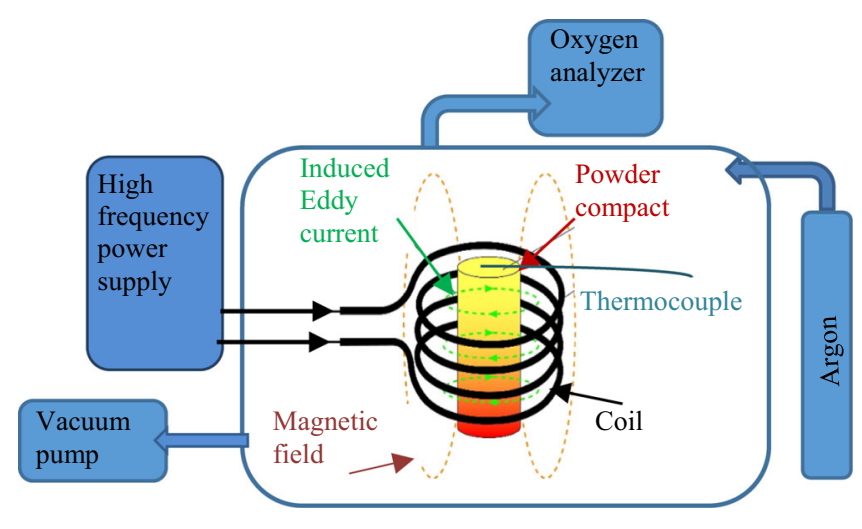

(a)

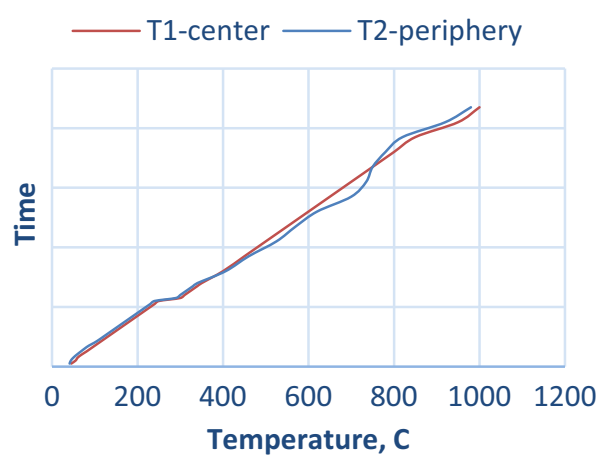

(b)

Fig. 1-Diagram of the experimental induction sintering setup $(a)$ and temperature profile during heating at the center and the periphery of the powder compact $(b)$. 
The $\mathrm{Ti}$ used for the experiments is a hydrogenation-dehydrogenation (HDH) powder with irregular morphology, particle size below $75 \mu \mathrm{m}$, and oxygen content of $0.25 \mathrm{wt}$ pct. Quantities of $60 \mathrm{~g}$ of powders were first compacted into cylindrical billets with a diameter of $40 \mathrm{~mm}$ using a steel die and uniaxial pressure. To minimize the density gradient during the powder pressing, holding time at the chosen pressure was used. In addition, the ratios of diameter/height of the powder compacts were in the ranges of 3.6/1 and 2.5/ 1 , which minimizes the density gradient through the sample height due to the uniaxial pressure used for the powder compaction. Three sets of powder compacts were prepared to conduct the experiments for the three substudies. The investigated process parameters are given in Table I. In study A, six samples with green density (GD) between 65.6 and 96.5 pct were prepared, using different combinations of uniaxial pressure and die temperature. Subsequently, the samples were heated to $1300{ }^{\circ} \mathrm{C}$, using HFIH. After the sample temperature reached $1300{ }^{\circ} \mathrm{C}$, the power was cut off, and the sample was removed from the induction coil. For study B and study $\mathrm{C}$, the GD of the powder compacts was kept constant, in the range of $89 \pm 1$ pct. In study $B$, the powder compacts were heated using $\mathrm{HFIH}$ to five different temperatures between $1000{ }^{\circ} \mathrm{C}$ and $1400{ }^{\circ} \mathrm{C}$ without holding time. In study $\mathrm{C}$, the IS temperature was kept constant of $1300{ }^{\circ} \mathrm{C}$, but the samples were held at this temperature for a period of time from 2 to 10 minutes.

The densities of the powder compacts and the sintered billets were quantitated via mass/volume ratios and the Archimedes method measurements, respectively. Oxygen analyses of the sintered samples were obtained by the inert gas infusion method using LECO equipment. A standard metallographic route was used to prepare the sintered material for scanning electron microscopy (SEM) in order to analyze the porosity distribution. The samples were further etched using Kroll's reagent, to reveal the grain structure. For the tensile test examination, at least three dog-bone-shaped specimens, with a rectangular cross section and dimensions $2 \times 2 \times 20 \mathrm{~mm}^{3}$, were cut from each sintered sample. The tensile test pieces are cut in a radial direction, as the three pieces within each sample fall in different regions of the sample vertical axis. The tensile test was done on Instron 33R4204 universal testing machine equipped with a strain gage. The strain rate was $8.33 \times 10^{-5} \mathrm{~s}^{-1}$. Further, the fracture surface of the tested tensile samples was analyzed by SEM.

\section{RESULTS AND DISCUSSION}

\section{A. The Effect of the Green Powder Compact Density}

The experimental heating curves and the calculated heating rates obtained during the IS of powder compacts with different GDs are presented in Figure 2. All samples, with an exception of sample A1, were able to heat up to $1300{ }^{\circ} \mathrm{C}$ in a relatively short time, between 85 and 250 seconds (Figure 2(a)). The calculated average heating rates varied from $3.5^{\circ} \mathrm{C} / \mathrm{s}$ to $15.3{ }^{\circ} \mathrm{C} / \mathrm{s}$ (Figure 2(b)). It is noticeable that the heating rates are slower in the initial stage of the HFIH, up to a temperature of approximately $1000{ }^{\circ} \mathrm{C}$, where also the variances of the heating rates are mostly observed. The reason for this variability is due to the amount of the porosity of each sample, as the gaps between the powder particles act as an insulator. Consequently, the powder compacts with higher GD, or less interparticle gaps, have higher conductivity in the initial stage of the

Table I. Experimental Parameters

\begin{tabular}{lccc}
\hline Study & Green Density, Pct & Induction Sintering Temperature, ${ }^{\circ} \mathrm{C}$ & Holding Time at $T_{\max }$, min \\
\hline A (Effect of Green Density) & $65.6 ; 69.7 ; 77.8 ;$ & 1300 & no hold \\
& $82.9 ; 88.5 ; 96.5$ & & \\
B (Effect of Sintering Temperature) & $89 \pm 1$ & $1000 ; 1100 ; 1200 ; 1300 ; 1400$ & $2 ; 4 ; 6 ; 8 ; 10$ \\
C (Effect of Sintering Time) & & $1300 \pm 30$ & 20 \\
\hline
\end{tabular}

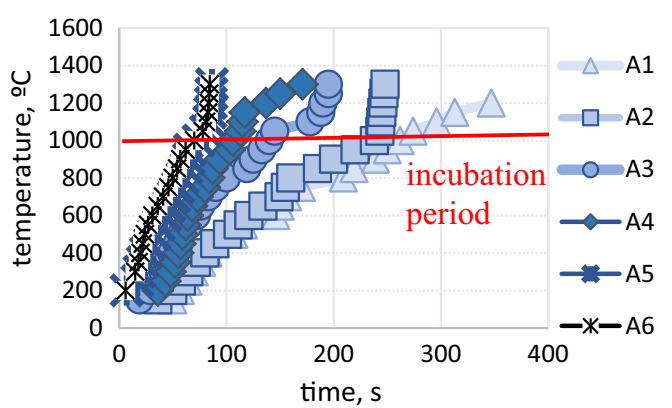

(a)

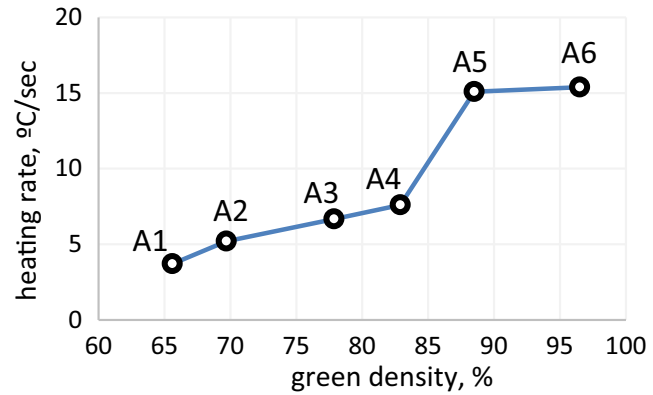

(b)

Fig. 2-Effects of the green density on the (a) experimental heating curves and $(b)$ average heating rates. 
HFIH, referred as an incubation period, ${ }^{[9,22]}$ when the coupling and the Eddy current are generated. The sluggish heating of sample A1 is clearly because of the significant amount of porosity present in its structure. It appears that this sample was in the incubation stage throughout the whole period of heating.

Earlier studies on using HFIH for consolidation of Fe-based powders ${ }^{[22,23]}$ and $\mathrm{Ti}$ powders ${ }^{[20]}$ found a similar relation between the powder compact density and the heating rates.

The main reason for the fast heating is the fact that the powder compact becomes a conductor of heat by itself when placed in the magnetic field created by the induction coil. In addition to the more direct and fast heating, there are minimal heat loses.

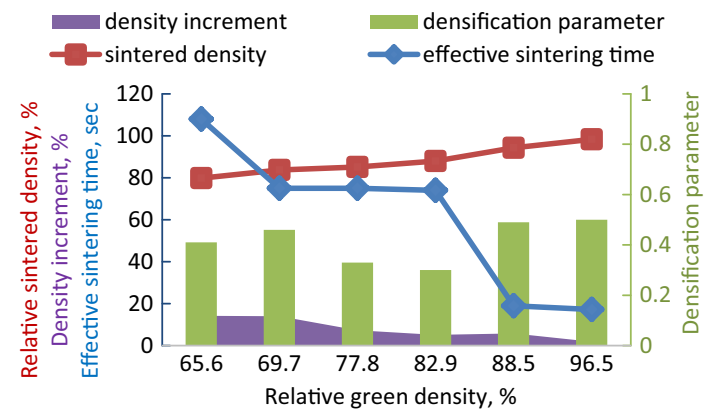

Fig. 3-Effects of the green density on the sintered density, densification parameter, density increment, and the effective sintering time.
Although cooling curves are not shown on the graph, it takes approximately 5 minutes for a compact to cool down below $200{ }^{\circ} \mathrm{C}$ due to the room temperature cooling. The overall length of the IS is therefore 7 to 13 minutes. These is significantly shorter than 8 to 12 hours for the conventional vacuum sintering commonly used for $\mathrm{Ti}$, with an average heating rate of $10{ }^{\circ} \mathrm{C} / \mathrm{min} \quad\left(0.17^{\circ} \mathrm{C} / \mathrm{s}\right)$ and cooling for several hours. ${ }^{[24,25]}$

The extent of the densification and consolidation of the Ti powder compacts gained by the IS were assessed by obtaining the values of the densification parameter, the density increase (Figure 3), and the distribution and morphology of the residual pores (Figure 4). Both figures clearly indicate that the sintered density and microstructure are strongly related to the initial powder compact density. The samples with low GD of 65.6 to 69.7 pct (A1 and A2) show significant density increase, in the range of 15 pct (Figure 3). Nevertheless, very little actual sintering is observed in these samples (Figure 4(a)). Sintering necks are developed between the neighboring powder particles, but the morphology of the original powder particles is still distinguished, and thus highly interconnected porosity network is observed.

Increase of the GD in the range of 77.8 to 82.9 pct results in a significant reduction of the pore network (Figure 4(b)) but the density increase of those samples was only 5 to 7 pct. Further increase of the GD to 88.5 pct resulted in a sintered microstructure with mostly closed pores having highly irregular shape and size in the range of 10 to $20 \mu \mathrm{m}$ (Figure 4(c)). The density increment of this sample is 6 pct and the final sintered density- 94.5 pct. Sample A6, with the highest GD of

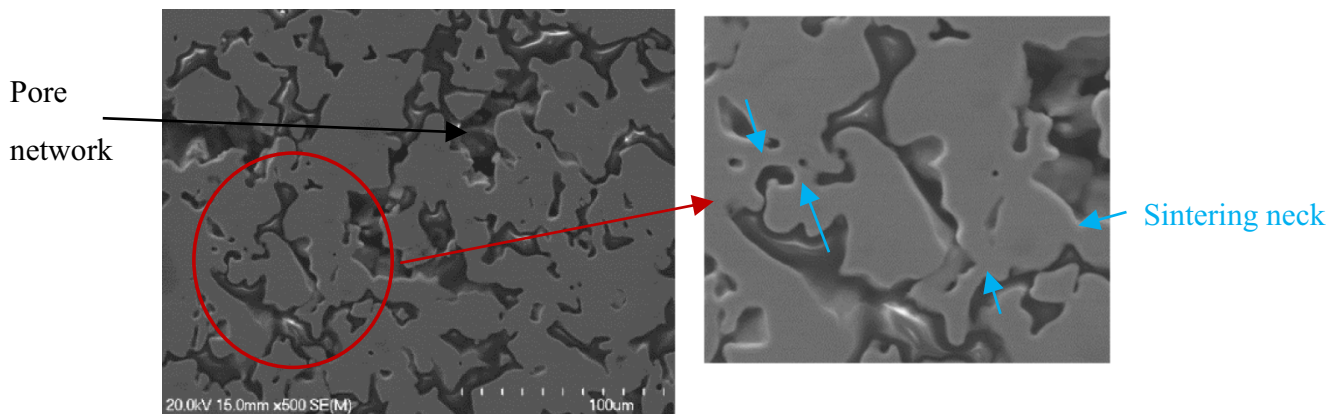

(a)

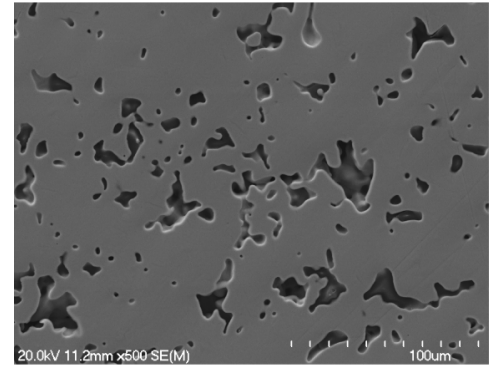

(b)

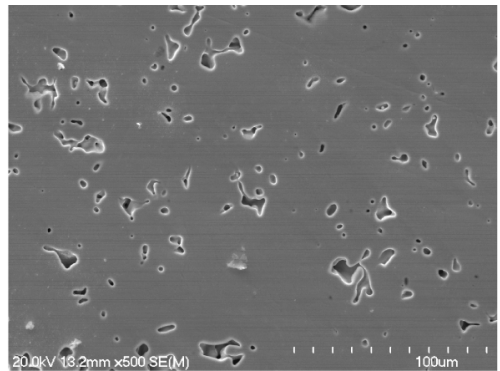

(c)

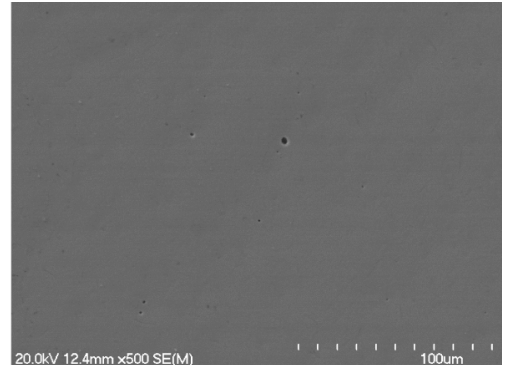

(d)

Fig. 4-SEM micrographs showing the porosity distribution of samples induction sintered to $1300{ }^{\circ} \mathrm{C}$, with starting green densities of: $(a) 65.6$ pct (A1), (b) 82.9 pct (A4), (c) 88.5 pct (A5), and (d) 96.5 pct (A6). 
96.5 pct, shows very little increase of density after sintering of (2.0 pct from Figure 3$)$, but significant reduction of the size of the pores of few microns and predominately spherical morphology (Figure 4(d)).

The densification parameter $(\Psi)$, calculated by the Eq. [2], shows that the densification did not proportionally increase with the increasing green density (Figure 3, bars).

$$
\Psi=\left(\rho_{\mathrm{s}}-\rho_{\mathrm{g}}\right) /\left(\rho_{\mathrm{t}}-\rho_{\mathrm{g}}\right)
$$

$\Psi$-densification parameter, $\rho_{\mathrm{s}}$-sintered density, $\rho_{\mathrm{g}}$ - green density, $\rho_{\mathrm{t}}$ - theoretical density

The greater densification of the samples with 65.6 to 69.7 pct GD is related to the powder particles rotation and repacking during sintering. ${ }^{[26]}$ In the initial stage of sintering, diffusion between the closely packed particles results in the formation of sintering necks, which is an unbalanced process because of the inhomogeneous packing of the powder particles. The formation of these necks leads to the formation of new grain boundaries with different associated energies depending on their crystallographic orientation. The unbalanced surface energies and inhomogeneous formation of necks generate torques in response to which the particles rotate or twist. In the powder compacts with lower density, there are more cavities between the particles, allowing greater rotation and repacking. Hence, there is a bigger potential for a density increase during the initial stage of sintering.

Another reason for the greater densification of the samples with lower green density is the length of the effective sintering time (Figure 3 ). The effective sintering time is referred to the heating time above the $\beta$-transus, where the diffusion process is significantly faster, which is above $900{ }^{\circ} \mathrm{C}$ for $\mathrm{Ti}$ with 0.25 pct oxygen. ${ }^{[27]}$ The effective sintering time calculated from Figure 2(a) shows that the samples with higher GD (A5) and (A6) were effectively sintered for only 20 seconds, while for the rest of the samples that were in the $\beta$-phase field, sintered for 50 to 100 seconds.

The porosity distribution of the samples with GD > 82.9 pct is found to be homogenous, while in the lower GD samples show more pore density in the peripheral areas and fewer pores in the center.

It is worth remarking that, when the green density is over 88 pct, the sintered density is comparable with those found in vacuum sintered $\mathrm{Ti},{ }^{[28-30]}$ where a similar temperature but much longer sintering time of 2 hours is used.

\section{B. The Effect of the Induction Sintering Temperature}

From study A, samples with GD of $89 \pm 1$ pct are used to assess the effect of the temperature (in the $\beta$ phase field, 1000 to $1400{ }^{\circ} \mathrm{C}$ ) on the properties of the IS titanium. Consolidation of the material was achieved in every condition (Figure 5). The sintered densities and the densification parameter increased with the temperature (Figure 5). However, the increase was less evident at lower temperatures $\left(1000{ }^{\circ} \mathrm{C}\right.$ and $\left.1100{ }^{\circ} \mathrm{C}\right)$, with densification parameter of 0.32 , and more pronounced as the IS temperature increased to $1200{ }^{\circ} \mathrm{C}, 1300{ }^{\circ} \mathrm{C}$, and $1400{ }^{\circ} \mathrm{C}$, showing values of the densification parameters of $0.4,0.48$, and 0.68 and sintered densities of $93.3,94.3$, and 96.5 pct respectively. Substantial consolidation is also evident from the representative IS microstructures shown in Figures 5(a) and (b). A typical microstructure for the samples sintered below $1200{ }^{\circ} \mathrm{C}$ is a mixture of short-range pore network and some closed porosity, with highly nonuniform size and irregular morphology (Figure 5(a)).

A significant change in the pore morphology is observed in the samples IS at higher temperatures of $1300{ }^{\circ} \mathrm{C}$ and $1400{ }^{\circ} \mathrm{C}$. The total area of the pores is significantly reduced. For the sample IS at $1400{ }^{\circ} \mathrm{C}$, microstructure shows mostly rounded pores with size in the range of 2 to $5 \mu \mathrm{m}$ (Figure 5(b)). However, no significant difference in the porosity distribution can be highlighted between the center and periphery of the sintered at different temperatures samples.

\section{The Effect of the Sintering Time}

The introduction of dwell time of 2 to 10 minutes at maximum IS temperature of $1300^{\circ} \mathrm{C}$ results in a considerable change in the pore morphology (Figures 6(a) and (b)) in comparison to the sample A5 (Figure 4(c)) where similar green density and sintering temperature but no holding time was applied. Specifically, after 2 to 4 minutes dwell, the number of the spherical pores increased while the irregular pores become significantly smaller in size and edge rounding occured (Figure 6(a)).

With the progression of the sintering during the prolonged 6 to 10 minutes dwell time, the sintered structures appear with mostly spherical pores with an average size of several microns (Figure 6(b)). The total amount of the porosity gradually decreases with the sintering time, evident also by the increase of the sintered density (Figure 6(c)). Nevertheless, no significant change of the densification parameter is seen with the increase of the sintering time from 6 to 10 minutes.

Comparing the effects of the IS temperature (Figure 5) and the IS time (Figure 6), the sintering at a higher temperature of $1400{ }^{\circ} \mathrm{C}$ is much more efficient than the increase of the sintering time, particularly noticeable with the values of the densification parameter. The samples sintered for 4 to 10 minutes showed a relative density of 95.7 pct and above, similar to those reported in the literature for high vacuum sintered Ti. $[28,29]$

\section{Overall Effect of the Process Parameters}

To fully understand the effect of the different processing parameters, a graph representing the sintering stage of each sample is presented in Figure 7. In accordance with the theory, ${ }^{[26]}$ the sintered materials were classified into three groups, identified by the level of consolidation or the sintering stage. Stage 1 is identified with the first signs of sintering, where multiple sintering necks between the neighboring powder 


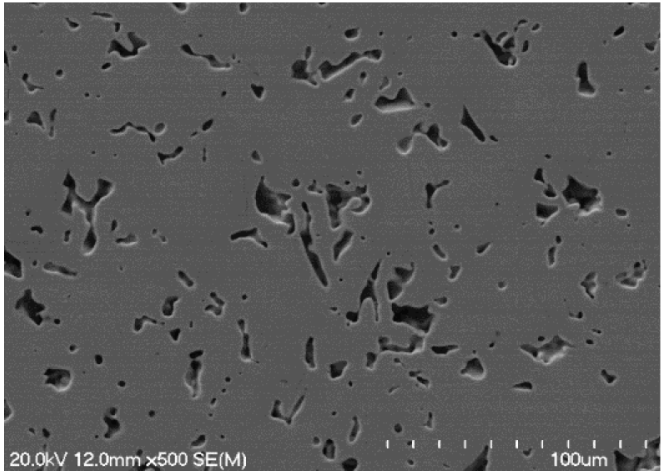

(a)

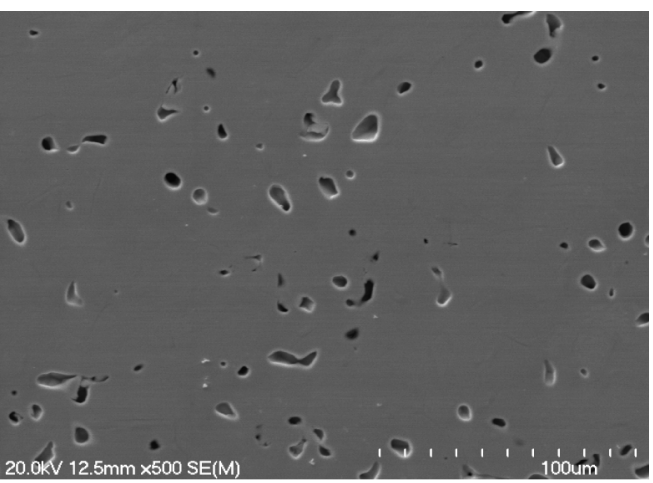

(b)

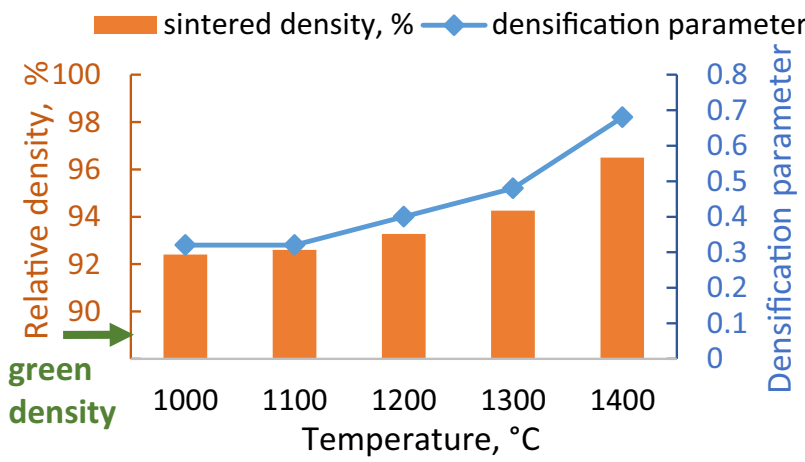

(c)

Fig. 5-The effect of the induction heating temperature on the porosity distribution (a) sample IS to $1000{ }^{\circ} \mathrm{C},(b)$ sample IS to $1400{ }^{\circ} \mathrm{C}$, and $(c)$ variation of the sintered density and the densification parameter.

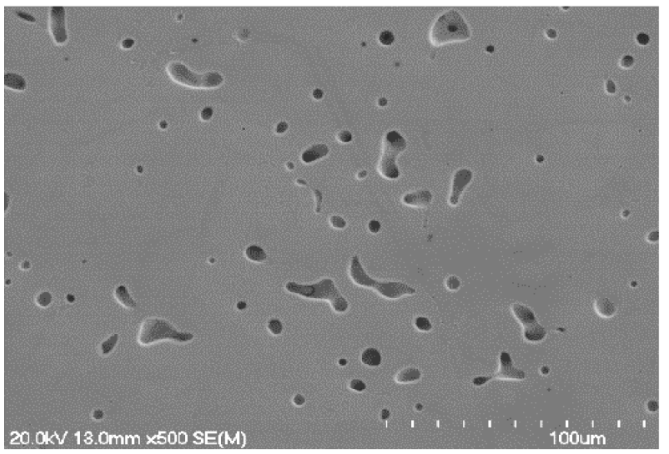

(a)

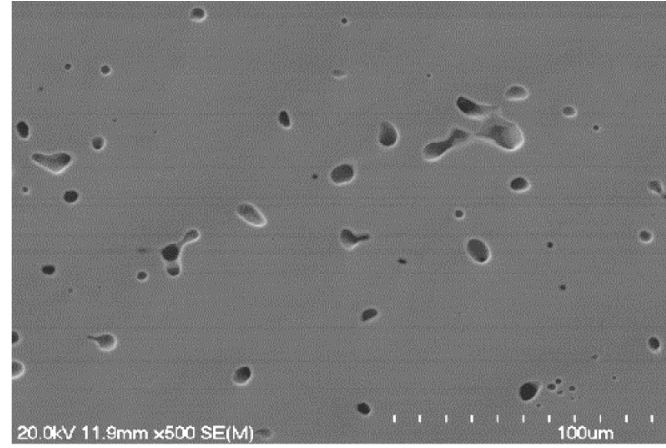

(b)

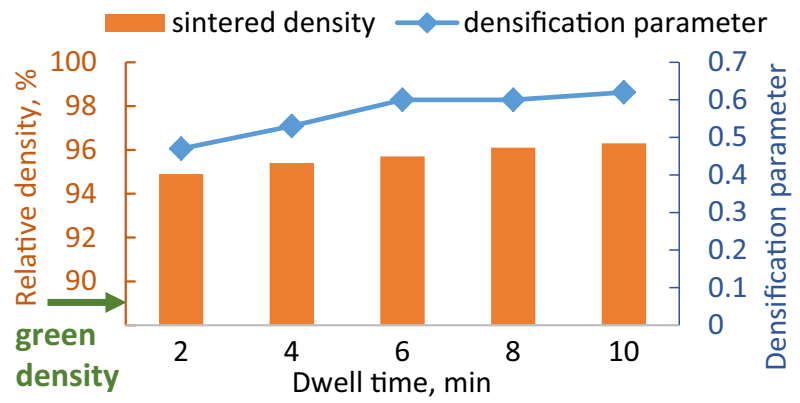

(c)

Fig. 6-The effect of the induction sintering time on the porosity distribution of samples IS at $1300{ }^{\circ} \mathrm{C},(a) 2$ min of dwell time, $(b) 10$ min of dwell time, and $(c)$ variation of the sintered density and the densification parameter. 


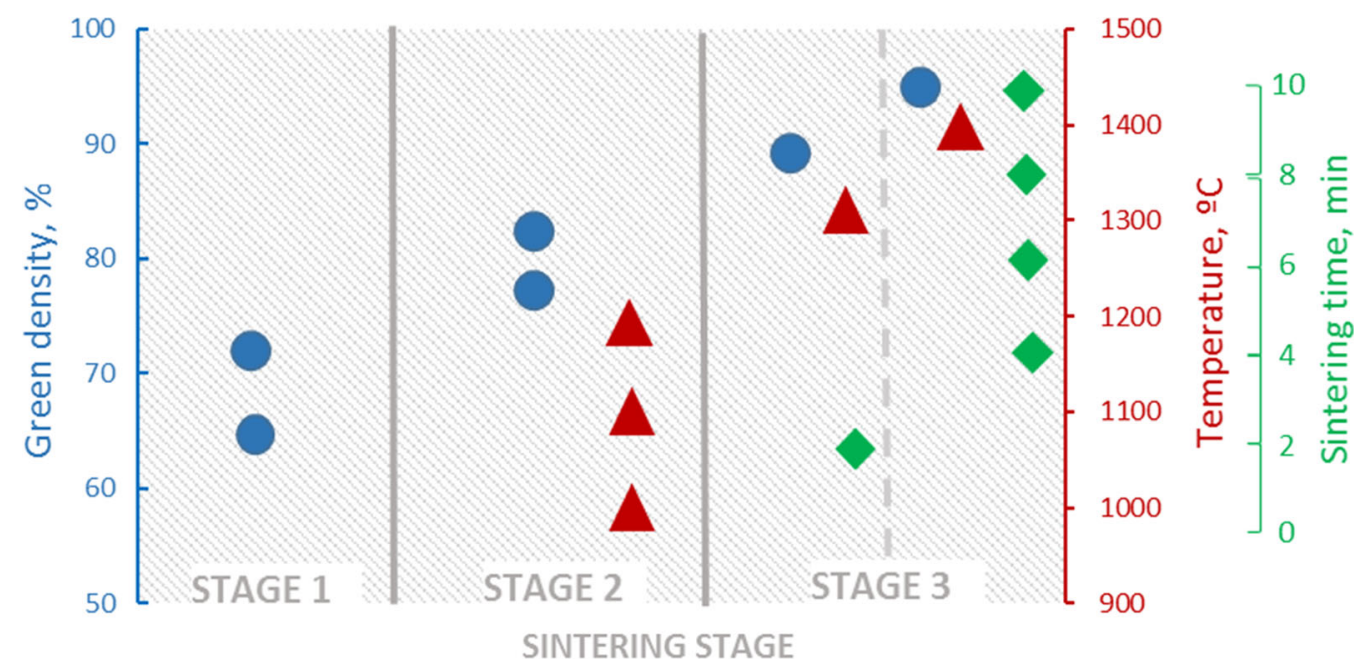

Fig. 7-Diagram of the predominant sintered structure found in the samples depending on the process conditions: green density-Series A (dots), temperature - Series B (triangles) and sintering time-Series C (diamonds).

particles are formed. Stage 2 is identified by extensive growth of the sintering necks but interconnected porosity is still largely evident. The final Stage 3 of sintering is characterized by the presence of mostly closed pores, where the powder particle boundaries disappeared. The final stage is divided into two substages, differentiating by the morphology of the pores- irregular and spherical.

Figure 7 demonstrates that the HFIH results in some level of sintering regardless of the process conditions. The GD is the parameter, with the greatest influence on the level of consolidation, where highly porous structures (Stage 1) are obtained if GD $<70.0$ pct. Structures with well-developed interparticle bonding but still considerable porosity (Stage 2) could be made, by controlling the GD or using lower IS temperatures of 1000 to $1200{ }^{\circ} \mathrm{C}$. Structures with properties of fully solid materials (Stage 3) are attained with GD > 89 pct, IS temperatures of $1300{ }^{\circ} \mathrm{C}$ or higher, and IS time of 2 to 10 minutes.

\section{E. The Effect of the Process Conditions on the Oxygen Pickup}

The presence of oxygen in the Ti-based materials greatly affects their mechanical properties, where oxygen pickup can easily occur during high-temperature processing. Figure 8 shows the effects of the $\mathrm{Ti}$ powder compacts GD, the IS temperature, and the IS time on the oxygen content of the sintered materials.

The oxygen content of the sintered samples is closely related to the GD of the powder compact (the dots in Figure 8). The oxygen increases from 0.29 to $0.46 \mathrm{wt}$ pct with the decrease of the GD from 96.5 to 65.6 pct. The significant oxygen pickup of the compacts with lower GD is mainly due to their fairly open structure and the larger air gaps between the powder particles. The air trapped in the powder compact is the main source of oxygen contamination. Since the sintering was done in a flowing argon atmosphere, the degassing of the powder compacts was not efficient during the purging of the

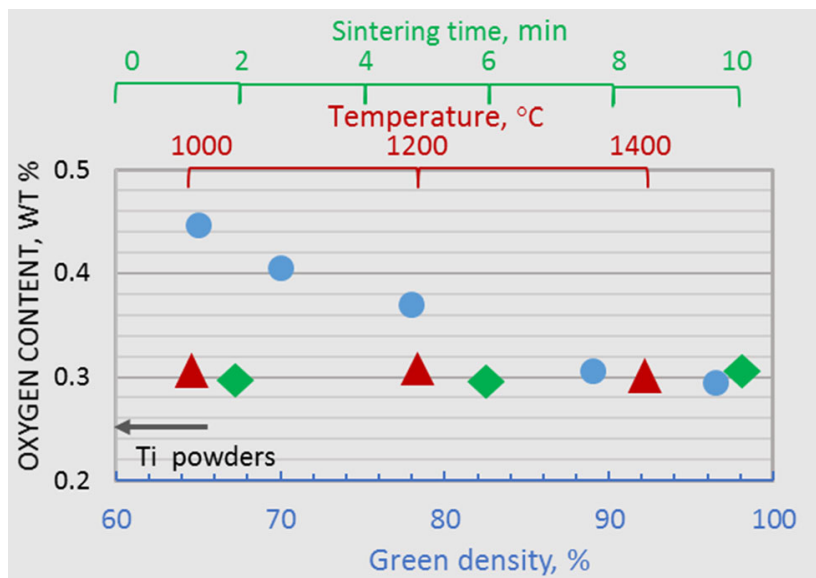

Fig. 8-Variation of the oxygen content with the processing parameters (green density - dots, temperature-triangles, and time- diamonds.

chamber, in such way as in the high vacuum sintering. However, for the samples with GD $>88.5$ pct, the oxygen pickup during IS remains minimal, in the range of 0.044 to 0.056 wt pet for an overall oxygen content of $\sim 0.3$ wt pct.

The increase of the IS temperature (the triangles in Figure 8) and the sintering time (the diamonds in Figure 8) does not have a significant effect on the oxygen pickup as the values are in the range of 0.040 to $0.063 \mathrm{wt}$ pct, reaching overall oxygen content in the range of 0.29 to $0.31 \mathrm{wt}$ pct, with no particular trend with temperature or sintering time. The observation that oxygen pickup during IS is independent of sintering temperature and time is similar to those in the earlier study. ${ }^{[20]}$ The short time that the material spends at high temperatures is the reason behind the limited oxygen pickup. These results show that the IS process can produce material with consistent oxygen content independently on the sintering temperature and time. Most of the IS samples have oxygen content in the range 
acceptable for the commercially pure Ti-Grade $3(0.35$ wt pct) and Ti-Grade $4(0.40 \mathrm{wt}$ pct $) .{ }^{[31]}$ The oxygen pickup and the oxygen content of the IS $\mathrm{Ti}$ shown in Figure 8 are lower then this reported for vacuum sintered $\mathrm{HDH} \mathrm{Ti.}{ }^{[32]}$

\section{F. The Effect of the Process Conditions on the Mechanical Behavior}

Irrespective of the sintering parameters, there is a significant improvement in the tensile strength and ductility of the IS samples compared to those of the green samples $(17 \mathrm{MPa})$, where the strength is purely due to mechanical interlocking between the powder particles. $^{[21]}$ Figure 9 shows that the variations of the properties are closely related to the process conditions. On the other hand, there is no large variability of the tensile properties within each sintered samples. As the tensile test pieces were cut from different locations along the vertical axis of each sample, this confirms that no significant gradient in the porosity distribution is present at the vertical direction of the sintered samples.

As expected, there is a strong relationship between the porosities of the sintered structures and the tensile properties (Figure 9(a)). The structures with large areas of pore network (Figure 4(a)), typical of Stage 1 (Figure 7), show YS of 110 to 190,150 to $230 \mathrm{MPa}$ UTS, and 2.5 pet elongation to fracture (Figure 9(a), $\mathrm{GD}<70 \mathrm{pct})$. In spite of the low tensile strength, each of these samples underwent yielding, confirming that sufficient interparticle bonding occurred during the short sintering cycle. The samples showing structures typical for Stage 2 of sintering (GD 78 to 82 pct or those sintered at $1000{ }^{\circ} \mathrm{C}$ to $1200{ }^{\circ} \mathrm{C}$ ) have comparatively higher YS and UTS, respectively, in the ranges of 290 to 400 and 320 to $480 \mathrm{MPa}$, where an improvement of the elongation to fracture to the average of 5 pct was also observed. The samples characterized with predominately closed porosity (IS at 1300 to $1400{ }^{\circ} \mathrm{C}$ or 2 to 10 minutes dwell time) have high YS and UTS, respectively 400 to 460 and 500 to $550 \mathrm{MPa}$ and show a significant improvement of the ductility. The elongation to fracture varies between 10 pct for the structures with irregularly and angular-shaped pores and 23 pct for those with rounded and mostly spherical pores.
Overall, the powder compacts GD has the greatest effect on both the strength and ductility of the IS samples (Figure 9(a). The IS temperature does not affect largely the strength but changes significantly the elongation to fracture, which gradually increases from 4.5 to 13 pct with the temperature increase (Figure 9(b)). It is clear that introducing a holding time at the maximum temperature of $1300{ }^{\circ} \mathrm{C}$ for samples with average GD of 89 pct leads to an increase of the YS, UTS, and the ductility (Figure 9(c)). After 2 minutes of sintering at $1300{ }^{\circ} \mathrm{C}$, the material is characterized with a YS of $475 \mathrm{MPa}$, UTS of $550 \mathrm{MPa}$ and elongation to fracture of 18 pct. However, further increase of the sintering time from 4 to 10 minutes does not remarkably increase the tensile properties.

The development of the sintered structures is also well represented by the fracture behavior of the tensile tested samples (Figure 10). The effect of the GD can be summarised using the representative A1 and A6 samples. Two main features are present in the fracture surface of the IS samples from series A: plane surfaces (green arrows) and rough, uneven surfaces with characteristics of a typical solid fractured material (black arrows). The relative amount of these features changes with the GD. The IS sample with the lowest GD of 65 pct (A1) shows only isolated areas of fractured surfaces, where the necking between the powder particles occurred (Figure 4(a)). The smooth surfaces are the network of interconnected pores due to the fairly poor consolidation of the materials. In contrast, the IS samples with a GD $>88.5$ pet fractured in a manner typical for a fully solid material (Figure 10(b)). The fracture occurred along the new grain boundaries formed at the former powder particle boundaries (Figure 10(b), red arrow), as well as through the grains, resulting in transgranular fracture (Figure 10(b), blue arrows).

The effect of the IS temperature on the fracture behavior is shown in Figures 10(c) and (d). In the samples induction sintered at lower temperatures of $1000{ }^{\circ} \mathrm{C}$ to $1200{ }^{\circ} \mathrm{C}$, a significant amount of nonconsolidated surfaces are observed along with the dimpled solid fractures at the newly developed sintering necks between neighboring powder particles (Figure 10(c)). For the samples sintered at higher IS temperatures of $1300{ }^{\circ} \mathrm{C}$ and $1400{ }^{\circ} \mathrm{C}$, the fracture surface is a

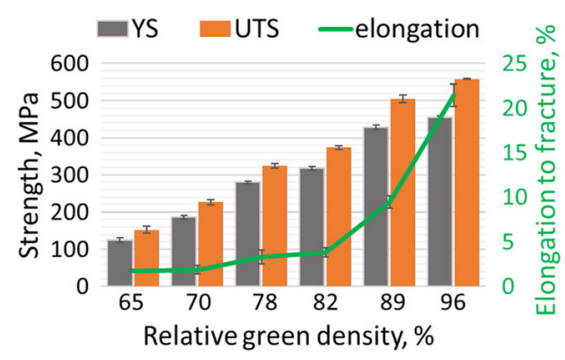

(a)

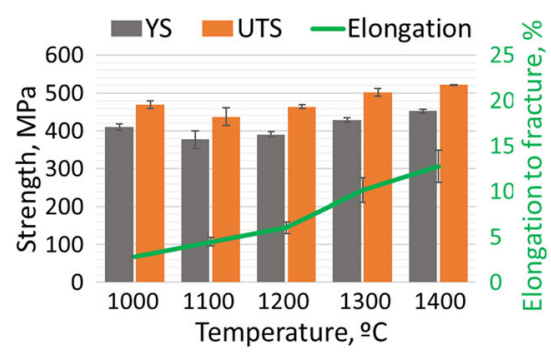

(b)

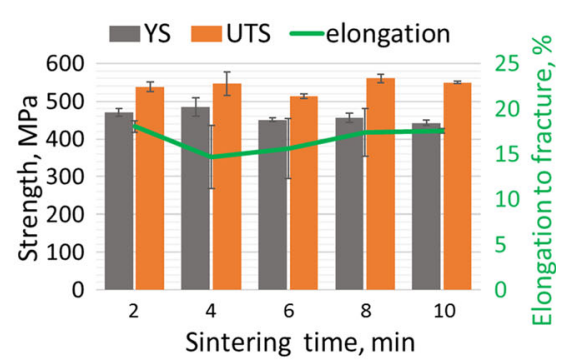

(c)

Fig. 9-Effect of the process parameters, $(a)$ green density, $(b)$ sintering temperature, and $(c)$ sintering time, on the tensile properties of the IS samples. 

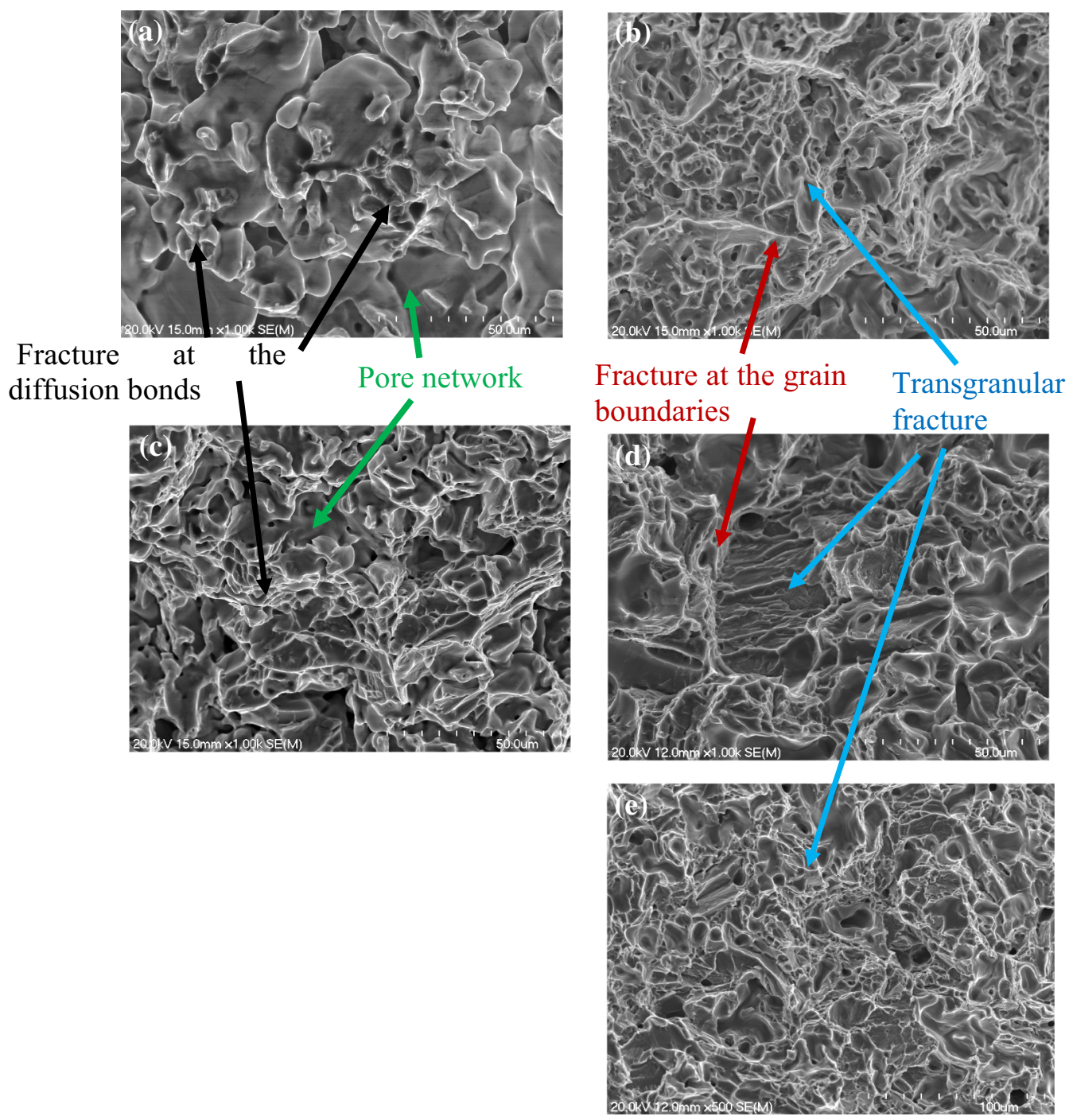

Fig. 10-Representative results of the fractographic analysis: $(a)$ and $(b)$ samples with GD of 65 pct (A1) and 95 pct (A6), respectively, sintered at $1300{ }^{\circ} \mathrm{C}$ without dwell time; $(c)$ and $(d)$ sintered at $1000{ }^{\circ} \mathrm{C}(\mathrm{B} 1)$ and $1400{ }^{\circ} \mathrm{C}(\mathrm{B} 2)$, respectively, without dwell time; and $(e)$ sintered at $1300{ }^{\circ} \mathrm{C}$ with 4 min of dwell time (C2) (Color figure online).

combination of transgranular and intergranular fracture (Figure 10(d)).

Regarding the effect of the sintering time, no noticeable difference in the fracture behavior was observed with increasing the dwell time from 2 to 10 minutes during sintering at $1300{ }^{\circ} \mathrm{C}$. Predominately transgranular fracture with dimpled features is observed, confirming the high ductile properties of these materials (Figure 10(e)).

\section{G. The Induction Sintering Mechanism}

The etched microstructure image, taken from Series A sample with GD of 65 pct and IS to $1300{ }^{\circ} \mathrm{C}$, shows that after sintering, the powder particles are still well distinguished, but significant necking occurred between the two neighboring powder particles P1 and P2 (Figures 11(a) and (b)). The original powder particle boundary disappeared, and new grain developed across the two neighboring powder particles.

The consolidation of particulate materials is governed by solid-state diffusion which is dependent on the species present on the surface of the powder particles. In particular, metallic powders are generally covered by a superficial oxide layer which slows down the sintering process. In the heating step of the sintering cycle, these oxide layers have to be broken or dissolved before (the much faster) metal to metal diffusion can occur. In the case of sintering in a resistance heating furnaces, this process is slow because the powder compact is heated gradually from the surface to the core, relying on conductive heat transfer from the outer to the inner part of the compact as a whole as well as from the surface to the core of each powder particle. However, during heating by HFIH, eddy currents are generated directly into the powder sample, and faster heating rates are 

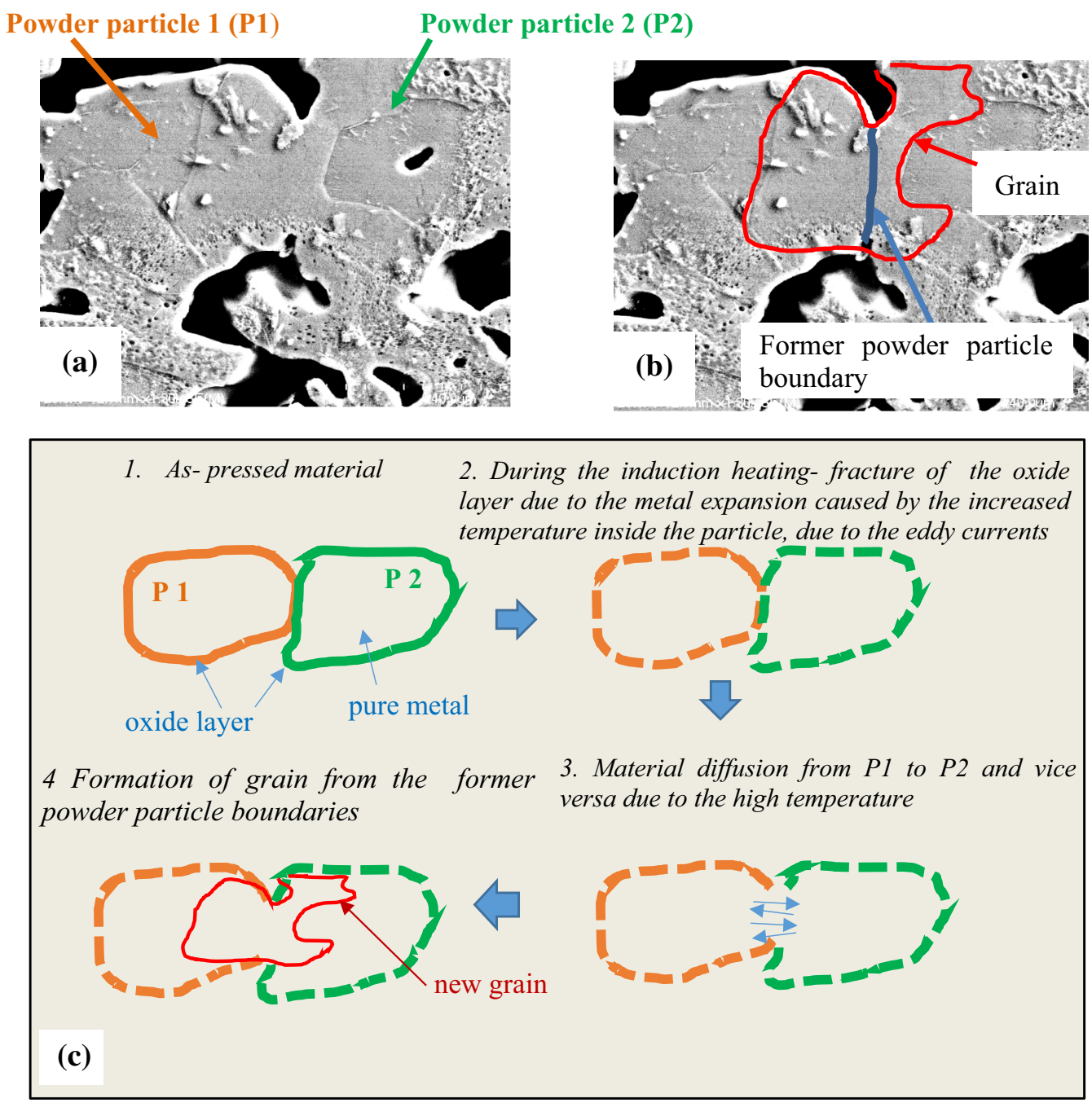

Fig. 11-Development of sintering necks during IS at $1300{ }^{\circ} \mathrm{C},(a)$ and $(b)$ SEM images of the microstructure of the sample with 65 pct green density (sample A1), and (c) schematic of the IS mechanism.

achieved. A mechanism for the fast diffusion and the development of grains from the powder particles during IS is then proposed (Figure 11(c)) based on the experimental observations. Specifically, the model considers two neighboring powder particles such as those shown in Figure 11(a)). During induction heating eddy currents are created simultaneously within each conductive powder particle, located within the penetration depth, without much influence from the presence of the superficial oxide layer, thus leading to a significantly faster increase of the temperature. The fast rise of the temperature causes thermal expansion (i.e. tensile stresses) of the powder particles leading to fracturing of the superficial oxide layer, due to the significant difference of its coefficient of thermal expansion, and consequently allowing the metal to metal interaction. The diffusion in $\mathrm{Ti}$ is significantly faster above the $\beta$ transus, allowing fast material transfer along the neighboring powder particles and consequently leading to the consolidation of the material and the formation of the final microstructure from the former powder particle boundaries.

\section{CONCLUSIONS}

This study demonstrates that high-frequency induction heating is a fast and efficient way for the consolidation of commercially pure Ti powders. The level of consolidation and the properties of the sintered material are highly influenced by the process parameters. Highly porous and highly dense structures are possible by varying the green density, induction sintering temperature, and the dwell time. Necking starts to occur in the very initial stage of sintering independent of the process conditions and the porosity of the material. Strong interparticle bonding is evident by the significant increase of the tensile strength and ductility, the characteristics of the fractured surface, and the formation of grains across the boundaries of the former powder particles. The oxygen pickup during the induction sintering is limited due to the short exposure to high temperatures. Selected combinations of process parameters enable the production of Ti material with properties comparable to those of wrought and powder metallurgy Ti-Grade 3 and Ti-Grade 4. 


\section{ACKNOWLEDGMENTS}

The financial support from the New Zealand Ministry of Business, Innovation and Employment (MBIE) through the TiTeNZ project (UOWX1402 research contract) is sincerely acknowledged.

\section{OPEN ACCESS}

This article is licensed under a Creative Commons Attribution 4.0 International License, which permits use, sharing, adaptation, distribution and reproduction in any medium or format, as long as you give appropriate credit to the original author(s) and the source, provide a link to the Creative Commons licence, and indicate if changes were made. The images or other third party material in this article are included in the article's Creative Commons licence, unless indicated otherwise in a credit line to the material. If material is not included in the article's Creative Commons licence and your intended use is not permitted by statutory regulation or exceeds the permitted use, you will need to obtain permission directly from the copyright holder. To view a copy of this licence, visit http://creat ivecommons.org/licenses/by/4.0/.

\section{REFERENCES}

1. F.H. Froes, S.J. Mashl, V.S. Moxson, J.C. Hebeisen, and V.A. Duz: JOM, 2004, vol. 56 (11), pp. 46-48.

2. Upadhyaya, G.S., Powder Metallurgy Technology and Equipment Selected Topics, in Materials Science Foundations, Upadhyaya, G.S., Editor. 2012, Trans Tech Publishers, Zurich. pp. 91-96.

3. Suárez, M., Fernández, A., Menéndez, G.L., Torrecillas, R., Kessel, H.U., Hennicke, J., Kirchner, R., and Kessel, T. Challenges and Opportunities for Spark Plasma Sintering: A Key Technology for a new genorations of materials. 2013. http://www.fct-systeme.de/dow nload/20140619125935/2013-InTech-Challenges.pdf.

4. Karayannis, V.G. Microwave sintering of ceramic materials. in 20th Innovative Manufacturing Engineering and Energy Conference (IManEE 2016), 23-25 Sept. 2016. 2016. IOP Publishing, Bristol.

5. E.T. Thostenson and T.W. Chou: Composites A, 1999, vol. 30, pp. 1055-71.

6. V.D. Buchelnikov, D.V. Louzguine-Luzgin, G. Xie, S. Li, N. Yoshikawa, M. Sato, A.P. Anzulevich, I.V. Bychkov, and A. Inoue: J. Appl. Phys., 2008, vol. 104 (1135051), pp. 1-10.

7. German, R.M., Rapid Heating Approaches, in Sintering: from empirical observations to scientific principles. Elsevier/ButterworthHeinemann, Amsterdam, 2014, pp. 405-11.
8. W. Hermel, G. Leitner, and R. Krumphold: Powder Metall., 1980, vol. 23 (3), pp. 130-35.

9. Conta, R.L., IEEE Trans. Ind. Appl., 1977. IA-13(4), pp. 330-34. 10. B.G. Plehanov: Porochkovaia Metall., 1992, vol. 12, pp. 96-99.

11. Krumphold, R., Hermel, W., and Leitner, G., Sintered MetalCeramic Composites. Proceedings of the Third International School on Sintered Materials, 6-9 Dec. 1983, 1984, pp. 127-38.

12. C. Civi and E. Atik: J. Alloys Compd., 2018, vol. 753, pp. 517-24.

13. U. Cavdar and E. Atik: Mod. Appl. Sci., 2010, vol. 4 (3), pp. $63-70$.

14. I.-J. Shon, B.-R. Kim, J.-M. Doh, and J.-K. Yoon: Ceram. Int., 2010, vol. 36 (6), pp. 1797-1803.

15. S. In-Jin, W. Hee-Ji, C. Sung-Wook, and K. Wonbaek: Mater. Trans., 2011, vol. 52 (9), pp. 1832-35.

16. M. Baig, H.R. Ammar, and A.H. Seikh: Mater. Sci. Eng. A, 2016, vol. 655 , pp. 132-41.

17. L. Bolzoni, E.M. Ruiz-Navas, E. Neubauer, and E. Gordo: Mater. Chem. Phys., 2012, vol. 131 (3), pp. 672-79.

18. S. Raynova, D.L. Zhang, and B. Gabbitas: Key Eng. Mater., 2012, vol. 520, pp. 289-94.

19. D.L. Zhang, S. Raynova, V. Nadakuduru, C. Peng, B. Gabbitas, and B. Robinson: Mater. Sci. Forum, 2009, vols. 618-619, pp. $513-16$.

20. Raynova, S., Study on Low-cost Alternatives for Synthesising Powder Metallurgy Titanium and Titanium Alloys, PhD thesis, in Engineering, Gabbitas, B., Bolzoni, L., and Yang, F., Editors. 2017, University of Waikato.

21. S. Raynova, D.L. Zhang, D. Polo, L. Gonthier, W. Egea, and V.N. Nadakuduru: Adv. Mater. Res., 2011, vol. 275, pp. 196-99.

22. L.S. Bulatova: Sov. Powder Metall. Met. Ceram., 1988, vol. 27 (7), pp. $547-50$.

23. Conta, R., Process for heating and sintering ferrous powder metal compacts with radio frequency magnetic field. 1975: USA.

24. I.M. Robertson and G.B. Schaffer: Powder Metall., 2010, vol. 53 (2), pp. 146-62.

25. M. Qian: Int. J. Powder Metall., 2010, vol. 46 (5), pp. 29-44.

26. R.M. German:Solid-state sintering fundamentals Sintering Theory and Practice, Wiley, New York, 1996, pp. 95-96.

27. Murray, L.S., Ti phase diagrams, in ASM Metal Handbook, Vol. 3. 1992. pp. 1741-70.

28. S.D. Luo, M. Yan, G.B. Schaffer, and M. Qian: Metall. Mater. Trans., 2011, vol. 42 (8), pp. 2466-74.

29. S.D. Luo, Y.F. Yang, G.B. Schaffer, and M. Qian: J. Mater. Process. Technol., 2014, vol. 214 (3), pp. 660-66.

30. Lou, J., Effects of powder conditioning on the quality, microstructure and mechanical properties of sintered titanium alloys (Chapter 6). in Engineering. 2015. http://researchcommons.waikato.ac. nz/.pp. $128-60$.

31. ASTM, ASTM B988- 13 Standard Specification for Powder Metallurgy (PM) Titanium and Titanium Alloy Structural Components.

32. L. Bolzoni, E.M. Ruiz-Navas, and E. Gordo: Mater. Des., 2014, vol. 60 , pp. $226-32$.

Publisher's Note Springer Nature remains neutral with regard to jurisdictional claims in published maps and institutional affiliations. 